\title{
Insights into integrating cumulative effects and collaborative co- management for migratory tundra caribou herds in the Northwest Territories, Canada
}

\author{
Anne Gunn, Don Russell and Lorne Greig ${ }^{1}$
}

\begin{abstract}
Globally, many migratory mammals are facing threats. In northern Canada, large annual ranges expose migratory caribou to an array of human activities, including industrial exploration and development. Recognition that responses to human activities can accumulate for caribou is long-standing, but is heightened by recent declines in caribou abundance. For example, since the mid-1990s, the Bathurst herd has declined by approximately $90 \%$, leading to severe harvest restrictions. More mines are being proposed and developed across the herd's annual range, raising questions about cumulative effects. Despite progress on assessment techniques, aboriginal groups are expressing strong concerns and frustration about gaps in responsibilities for who should monitor, mitigate, and manage cumulative effects. The core of the concern is sustainability and the related trade-offs between industrial developments relative to continued access to healthy caribou for harvesting. We offer insights into how these concerns can be addressed by building on existing concepts (adaptive management) and approaches (herd management).
\end{abstract}

Key Words: adaptive management; Arctic Canada; cumulative effects; migratory caribou; mitigation; monitoring

\section{INTRODUCTION}

Caribou are an essential part of the culture for many aboriginal people who also depend on caribou harvest. Aboriginal people have repeatedly voiced concern about cumulative effects of industrial exploration and development on caribou. Their concerns are centered on displacement of caribou from seasonal ranges and effects on caribou health. Conserving migratory animals can be especially difficult (Berger 2004) because their migrations between seasonal ranges can expose them to sites of human activities, even when such sites are highly dispersed. In northern Canada, migratory tundra caribou Rangifer tarandus typically have large annual migrations of hundreds to thousands of kilometers between their seasonal ranges. While caribou are exposed over the spatial scale of their annual range, they also respond to stresses over their lifetime, which is typically $\sim 15 \mathrm{yr}$ for an adult female.

Cumulative effects assessment is a part of environmental impact assessment that examines the combined impact of the individual effects of multiple stresses from human activities additional to natural environmental effects, including climate. Although relatively simple in concept, cumulative effects have proven somewhat intractable in practice, partly because attention tends to focus on incremental effects, rather than the condition and capacity of the environment to absorb those incremental effects (Duinker and Greig 2006, Kennett and Woynillowicz 2007, Canter and Ross 2008, Noble 2010, Greig and Duinker 2011).

Lack of progress over cumulative effects in the Canadian Northwest Territories (NWT) is becoming progressively more apparent. In 1999, aboriginal organizations, industry, and government agencies developed the Northwest Territories Cumulative Effects Assessment and Management Strategy and Framework, and the NWT Cumulative Impact Monitoring Program. After more than a decade, progress on accounting for cumulative effects in monitoring, mitigation, and management has lagged. This lack of progress and deficiencies in the management of cumulative effects have led to fears about the sustainability of the Bathurst caribou herd as voiced by the Lutsel K'e Dene First Nation and Tlicho Government during the Gahcho Kue mine environmental assessment (Lutsel K'e Dene First Nation 2012, Tlicho Government 2012). Organizations noted that the only mitigation for cumulative effects was further harvest restrictions, which highlighted the lack of independent oversight for mitigation and monitoring of project-specific impacts, and observed that Territorial and Federal governments have not yet established a clear management framework that can be applied in the NWT.

The pressing need to manage cumulative effects was also recognized by government wildlife management agencies. The Government of the Northwest Territories (GNWT) in its Caribou Management Strategies (2006-2010 and 2011-2015) committed to developing cumulative effects modeling tools for barrenground caribou (GNWT 2011). However, both strategies had only relatively high-level policies stated and no clear path for how decisions could be made about priorities and trade-offs among land and resource uses on caribou herd ranges. Additionally, neither monitoring nor mitigation for cumulative effects was described.

Based on insights gained during our collective experience in cumulative effects and caribou management, we identified the need for a regulatory and institutional framework to inform decisions about the trade-offs between the major factors that influence the sustainability of caribou herds. Here, we propose a framework for cumulative effects monitoring and management for migratory tundra caribou. We have two objectives. First, we show how cumulative effects assessment, monitoring, and mitigation can be linked through adaptive management. Monitoring, as applied in the framework, is used to assess effectiveness of mitigation and management decisions to determine how mitigation can be adjusted. To develop this framework, we describe requirements for monitoring as well as approaches available to mitigate cumulative effects beyond simply restricting harvest. Mitigation is the suite of actions to modify 
effects of human activities. Mitigation for cumulative effects includes development of project-specific mitigation, and actions at the herd and landscape scale to reduce vulnerability and increase resilience.

Our second objective is to show how adaptive management of cumulative effects can be implemented by incorporating cumulative effects into herd-level monitoring, assessment, and decision-making. Setting cumulative effects into a herd management context re-asserts that the goal of environmental impact assessment is sustainability of caribou. While an individual project proponent is required to assess cumulative effects, the very nature of cumulative effects is a joint (shared) responsibility with previous and future development proponents and resource co-management agencies. Thus, it makes sense to provide a framework for shared responsibilities that clearly identifies regulatory responsibilities and authorities. We have used linkage diagrams to emphasize the relationships between the components. While we use the Bathurst herd as an example, integrating cumulative effects monitoring and mitigation into herd management planning is transferable to other migratory tundra caribou herds.

Adaptive management is a relatively broad and evolving approach to complex ecological and socioeconomic systems (Walters and Holling 1990, Lee 1999, Monroe et al. 2013; C. Murray and D. R. Marmorek, unpublished manuscript: http://www.adaptivemanagement. net/sites/default/files/Adaptive $\% 20$ management $\% 20 \mathrm{~A} \% 20$ spoonful $\%$ 20of $\% 20$ rigour $\% 20$ helps $\% 20$ the $\% 20$ uncertainty $\% 20$ go $\% 20$ down. pdf). While we do not explore how decisions could be made through adaptive co-management, we acknowledge it is complex (Monroe et al. 2013). It requires collaborative input as communities, governments, and industries undertake the implementation of a cumulative effects framework with consultation to ensure that operational details are consistent with "respecting" caribou in the context of the knowledge and values of aboriginal people. Nor do we explore landscape management using limits and offsets for development, despite our recognition that these approaches cannot be postponed much longer.

The statements made during environmental assessments for the most recent mine assessments on the NWT range of the Bathurst herd highlight the concerns and fears of caribou harvesters. The extent of the Bathurst caribou herd decline between 1996 and 2009 and the continued decline of breeding females during 20092012 (Boulanger et al. 2014) reveals that the Bathurst herd is highly vulnerable to further decline despite the severe harvest restrictions already imposed.

\section{BACKGROUND}

\section{Abundance and distribution of the Bathurst caribou herd relative to developments}

The Bathurst herd (Fig. 1) has declined from 360,000 in 1996 to 31,600 in 2009 (Boulanger et al. 2011). The decline followed a peak of high numbers, a typical part of the abundance cycle of migratory tundra caribou (Gunn 2003). A complex of interacting factors drive the cycles, including changes to forage, accumulated effects of forest fires on the winter ranges, harvesting, predation, and parasitism. During the decline, productivity and adult cow survival decreased (Boulanger et al. 2011), which likely increased the herd's vulnerability to additional environmental stresses.
Fig. 1. Annual range of the Bathurst caribou herd, showing the locations of current and proposed mines and access roads.

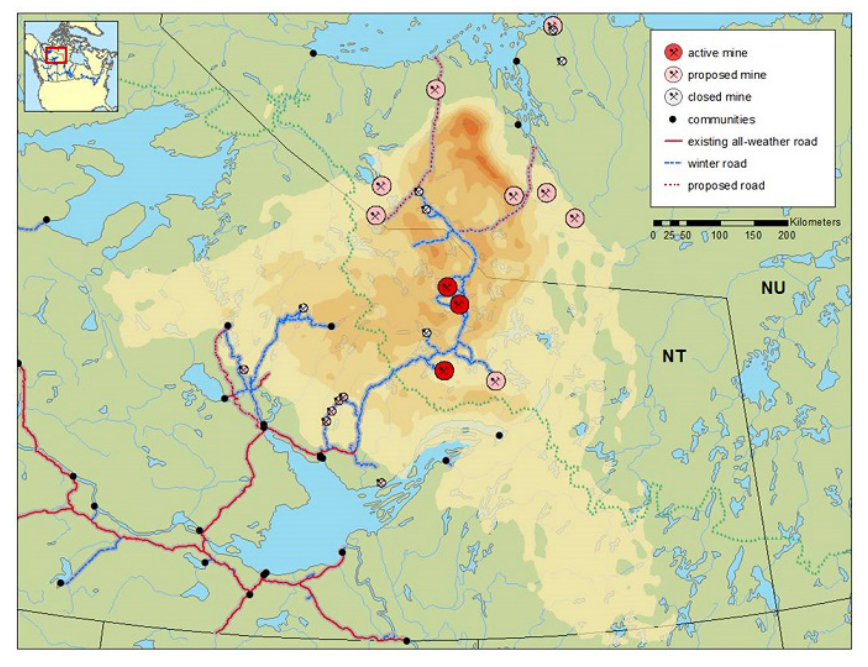

The decline coincided with an increase in mining exploration and development. Although mining exploration had been occurring for decades, the discovery of diamonds in 1991 triggered a surge in exploration, with an increase in camps, aircraft, and helicopters on the tundra ranges of the Bathurst herd, which are the precalving to autumn ranges. At the peak of exploration in 1993, $118,124 \mathrm{~km}^{2}$ of new claims had been staked in the NWT (G. Bouchard, Natural Resources Canada, personal communication). The diamond exploration led to the development of three mines and a fourth mine undergoing review on the NWT range of the herd (Fig. 1), with a diamond mine in Nunavut.

The Bathurst herd's pre-calving migration is led by the cows moving north to their traditional calving grounds on the tundra. During post-calving and summer, the caribou tend to move clockwise from the calving grounds, southwest toward the treeline by late summer and autumn. During this movement, they encounter industrial development and exploration sites. Aboriginal elders have stated concerns about caribou avoiding mines (Lutsel K'e Dene First Nation 2012). This zone of influence within which caribou, especially cows with calves, avoid infrastructure and human activity is up to $\sim 15 \mathrm{~km}$ for an active mine (Boulanger et al. 2012).

During a cumulative effect assessment for the Gahcho Kue diamond mine in the NWT (De Beers 2012), a catalog of previous and existing developments was compiled, which included 551 developments (exploration camps, mines, communities, quarries) with a total area of 76,157 ha plus $2491 \mathrm{~km}$ of transmission lines and roads. Most of the known start and end dates for actual work were available only from 1996 through 2010 and thus, the compilation did not include the peak of the diamond exploration in 1993. De Beers (2012) reported that the direct footprint of those developments, including the Gahcho Kue proposed mine, compared to pre-development conditions, would cumulatively reduce caribou habitat up to $7.3 \%$ on the autumn range. While there are limitations in relating the scale of these projected changes in habitat availability to changes in abundance of 
caribou, it is worth noting that a relatively simple population model based on productivity and survival (De Beers 2012:7-139) projected that "cumulative effects from development resulted in a $12.2 \%$ reduction in projected final herd abundance relative to reference conditions" over 30 years.

De Beers (2012) estimated the exposure of caribou cows to the disturbance sites on the summer and autumn ranges. The movements of caribou cows fitted with satellite collars from the Bathurst herd were mapped to determine when they encountered development sites on the summer to autumn ranges (De Beers 2012). Annually, the mean number of collared cows available was $14 \pm 0.9$ (SE) cows. From 1996 to 2009 , the cows annually spent an average of $10 \pm 14.3$ (SD) days or $7 \%$ of their time (summer to autumn) within the development's estimated $15-\mathrm{km}$ zone of influence. The amount of time within the zone of influence increased from $1.9 \%$ in 1996 to a peak of $12.9 \%$ in 2004, and then decreased to $10.1 \%$ in 2009 as the number of active land-use permits declined, suggesting that monitoring land-use permits could be used to trigger changes in mitigation.

As abundance increases or decreases, caribou distribution also changes. During the 2000-2010 decline, the southern boundaries of the Bathurst herd's winter range contracted $>200 \mathrm{~km}$ northward (Gunn et al. 2011). However, there did not appear to be contraction in the use of calving and summer ranges between 1996 and 2005 (Gunn et al. 2011). The fidelity to calving and summer ranges suggests that a development site situated in or near either of these seasonal ranges would likely have predictable caribou encounter rates regardless of population size.

\section{Herd management}

Management planning for the Bathurst herd has occurred at intervals since 1988, with plans proposed in 1994 and 2004, although they were not implemented. In 2005, the Tlicho Land Claim Act established the Wek'èezhìi Renewable Resources Board (WRRB), whose authority included the Bathurst caribou herd. The rapid decline of the herd led to a Ministerial decision to stop hunting and a WRRB public hearing from which the Tlicho Government and GNWT developed a revised joint management proposal. In October 2010, the WRRB recommended harvest restrictions, which reduced aboriginal harvest from several thousand to 300 caribou. WRRB also recommended that the Tlicho Government and the NWT Department of Environment and Natural Resources work on an adaptive co-management framework for a Bathurst caribou management plan, which in 2014, is still underway (http://www.wrrb.ca/node/560).

\section{A RESPONSE FRAMEWORK FOR ADAPTIVE MANAGEMENT OF CUMULATIVE EFFECTS}

We use a framework to link an adaptive management cycle (Racher et al. 2011) with the different scales of monitoring and the role of the cumulative effects assessment in monitoring design (Fig. 2). We recognize that adaptive management is "a systematic and rigorous approach for learning through deliberately designing and applying management actions as experiments" (C. Murray and D. R. Marmorek, unpublished manuscript: $\underline{\text { http:// }}$ www.adaptivemanagement.net/sites/default/files/Adaptive $\%$ 20 management $\% 20 \mathrm{~A} \% 20$ spoonful $\% 20$ of $\% 20$ rigour $\% 20$ helps $\% 20$ the $\%$ 20uncertainty $\% 20 \mathrm{go}_{0} \% 20$ down.pdf). Here, we refer to passive adaptive management in the sense that alternative treatments (application of mitigation actions) are most likely to be evaluated sequentially rather than through parallel comparison of alternatives across different sites. Although most learning about mitigation would preferably come from experimental designs statistically comparing several treatments at the same time, for example, levels or types of dust control, this is not necessarily practical for operational mines to achieve. In time, some opportunities for parallel experimentation at different project development sites could arise but would require collaborative efforts by proponents across multiple development sites. We expect that thoughtfully linking mitigation and monitoring to test sequential mitigation actions will still provide feedback on the mitigation effectiveness. To date, the Wek'èezhìi Land and Water Board relies on adaptive management only for aquatics monitoring and mitigation (Racher et al. 2011).

Fig. 2. Response framework for cumulative effects illustrating monitoring design.

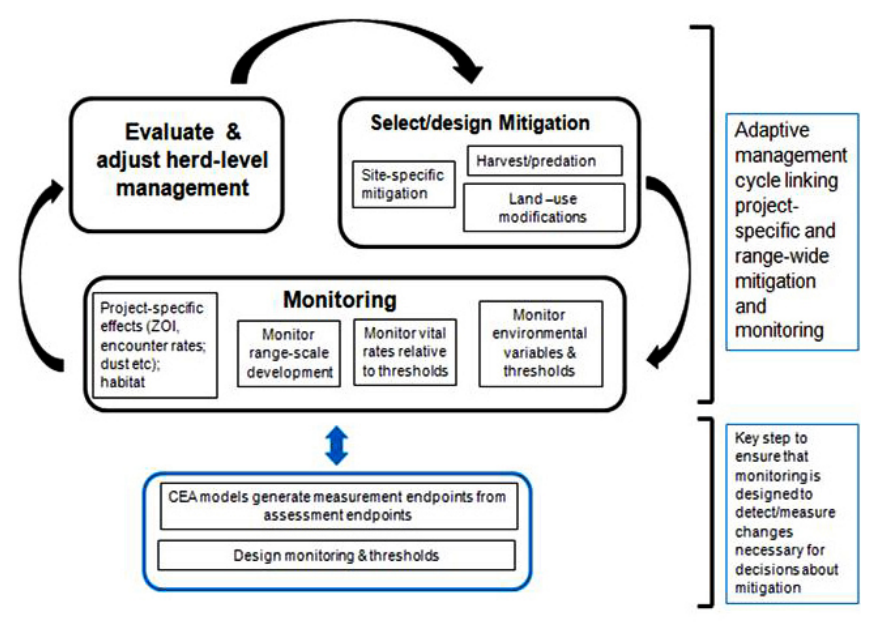

For the caribou response framework (Fig. 2), the environmental assessment establishes the assessment and measurement endpoints. Assessment endpoints are general statements that relate to goals such as sustainability of populations. Measurement endpoints are typically quantifiable and require selecting appropriate indicators. We agree with Suter (1990) that it is essential to define endpoints precisely. However, with sufficient clarity, endpoints of monitoring can also be narrative statements, which can help in incorporating community observations. The four scales of monitoring to assess and adjust (increase or reduce) mitigation are (1) project specific, (2) range-wide development, (3) herd-level vital rates, and (4) environmental indicators (Fig. 2). Ecological process modeling of caribou response to multiple stresses (natural and anthropogenic) provides a foundation to support rigorous monitoring design. The model(s) include representations of processes that are established from prior work and hypothesized interactions between caribou and proposed human activities, including proposed mitigation. They are revised in light of the monitoring results to support monitoring design for the next iteration of the adaptive management cycle.

The proposed framework provides a systematic approach to evaluating the efficacy of project mitigation and herd-level management and adjusting these management initiatives in light 
of monitoring results. This requires monitoring design to include explicit consideration of hypotheses, objectives, statistical power, and thresholds (levels to trigger decisions). We use calf survival as an example to outline the process to select monitoring indicators (Fig. 3), which requires estimating effect size (how much the indicator is predicted to change) in relation to the sensitivity of the sampling method to estimate whether the monitoring would be capable of detecting an effect of a given size. If the statistical power analysis indicates that an effect is unlikely to be detected, then either the precision can be improved (e.g., by increasing sample size or improving methodology) or an alternative, more sensitive indicator can be selected from the pathway analysis used to predict the effect. For example, if the input for the model used to predict calf survival had required information from encounter rates, foraging time, or growing degree days in spring, then they could be considered as surrogate indicators for calf survival. Once a suitable indicator is identified, the models can be also used to simulate thresholds for the monitoring indicators.

Fig. 3. Flow chart illustrating an approach to selecting indicators for measurement endpoints.

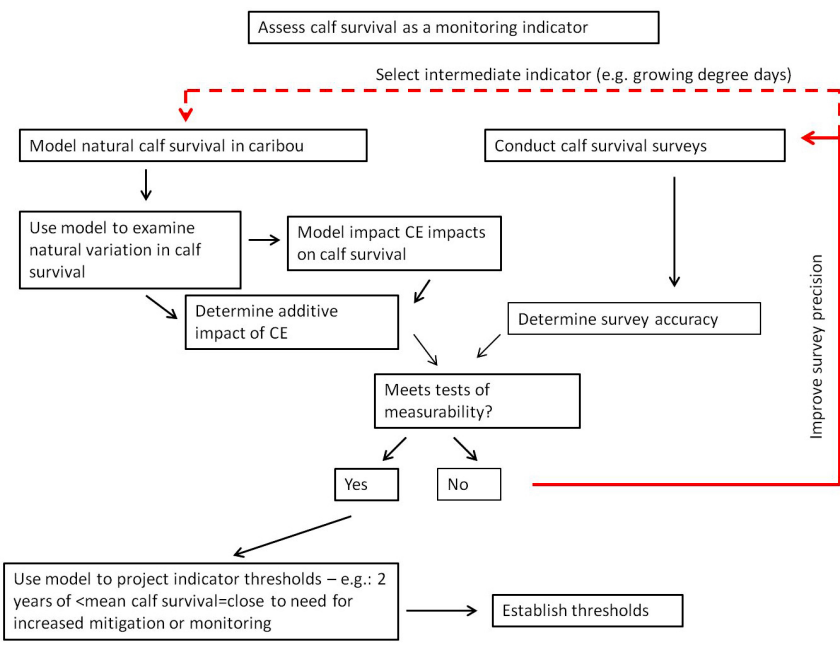

Mitigation includes activities undertaken to avoid, minimize, restore, or offset effects of industrial exploration and development on wildlife, wildlife habitat, and the people who use or value them. Relatively little is written about mitigation of cumulative effects. As an example, mitigation listed in oil and gas plans (Lutz et al. 2011, Jakle 2012) does not distinguish between mitigation for project-specific effects and cumulative effects. We suggest that drawing a distinction between project-specific and cumulative effect mitigation is essential because it recognizes that while the effects are interconnected, the responsibility for monitoring and guiding decisions about implementation differs. Mitigation can be organized as a hierarchy from avoidance through minimization to compensation (both on-site and off-site actions). Examples are listed in a mitigation plan developed for wildlife and natural gas development (Jakle 2012) and for mule deer and energy development (Lutzet al. 2011). There is no counterpart document for migratory tundra caribou.
We also observe that adaptive management is rarely applied to estimate the effectiveness of mitigation for northern caribou. For example, the zone of influence around the operational diamond mines is a residual effect after some mitigation (e.g., noise and dust control). However, there has been no effort to determine if mitigation can be intensified to reduce the extent of the zone of influence. In other words, the residual effect after current mitigation practices, i.e., a $15 \mathrm{~km}$ radius around existing diamond mines with reduced caribou occupancy, has become the accepted "norm" (e.g., De Beers 2012).

There is a hierarchy for mitigation of cumulative effects: tradeoffs, landscape-scale mitigation, and project-specific mitigation (Fig. 4). Trade-offs might include, for example, actions to increase caribou survival (through harvesting and predator control) relative to permitting developments. Landscape-scale mitigation includes exchanging land, purchasing or leasing of sensitive areas (Copeland et al. 2009), controlling the number and distribution of development activities, or modifying start-up dates and duration. The third category of cumulative effect mitigation is modifying project site activities. We include more examples of project (site-specific) mitigation (Fig. 4) because these are readily available within individual project assessments and their corresponding operational plans (e.g., De Beers 2012).

Fig. 4. The three categories and examples of cumulative effects mitigation: offset (harvest, predation), land use (modify the amount of landscape occupied by development over time and space), and project-specific mitigations.

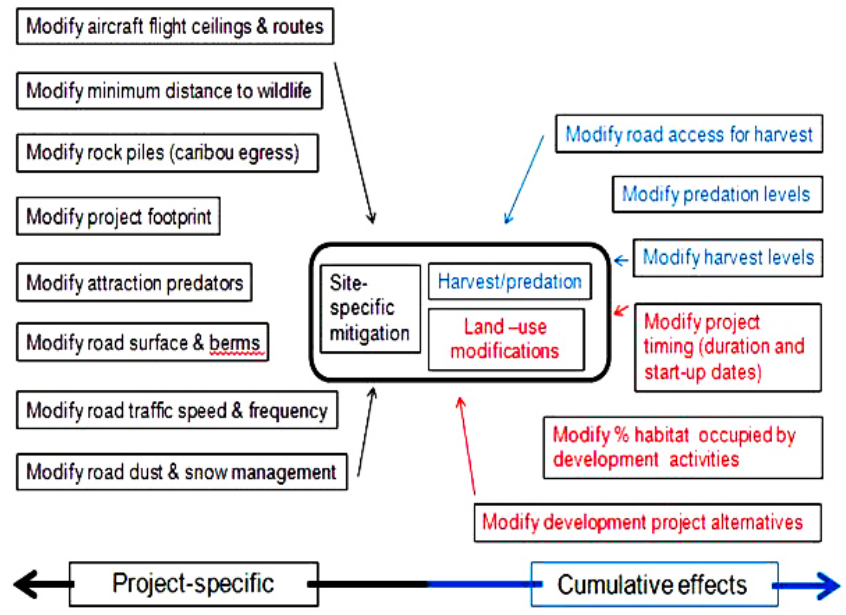

For all three categories, mitigations should be specific, matched to monitoring indicators and threshold levels, and applied to herd management in an adaptive management process (Fig. 4). Unfortunately, the linkage between the proposed effect, its mitigation, and monitoring to determine effectiveness of mitigation (reduction or removal of effect) is normally weakly described or absent, primarily because mitigation has only been applied on a project-specific basis. In most cases, although mitigation has been undertaken, it has not been tested for effectiveness, and therefore, there is no opportunity to apply an adaptive management approach. Further, mitigation applied on a project-specific basis seldom involves formal knowledge transfer 
between projects and among proponents, with little coordinated application of the mitigation, and no joint testing of effectiveness. It is also important to differentiate mitigations that are relatively fixed (e.g., corridor routing, road width, berm height) as opposed to mitigation actions that can be modified (e.g., frequency, degree, and extent of activities such as watering roads to reduce dust), a critical feature of an adaptive management approach.

\section{INTEGRATING CUMULATIVE EFFECTS AND HERD MANAGEMENT}

The goal of cumulative effect assessment is sustainability of a valued ecosystem component such as caribou. Sustainability is also a primary goal of herd management plans (and has to be defined in that context). To achieve that goal requires an adaptive management approach such that the effectiveness of mitigation or management actions is determined through monitoring, and actions are adjusted if necessary. For example, as climate changes, and those trends modify caribou responses to mitigation, adjustments to mitigation, including trade-offs, will be required. Thus, we introduce the use of thresholds, i.e., qualitative or quantitative values of the monitoring indicators that are used to trigger decisions about mitigation or management actions (Fig. 4). Thresholds should be tied to the range of natural variation for environmental variables (i.e., biological and measurement uncertainty). For other indicators such as harvest or land use, we envision a collaborative approach such as that developed by the Porcupine Caribou Management Board (2010) for its harvest management plan.

Caribou integrate the effects of a myriad of factors that in themselves are additive, compensatory, and synergistic; thus, complexity and uncertainty abounds. Environmental conditions and anthropogenic changes are inter-related (Fig. 5); a dry summer affects caribou directly and can intensify project-specific effects. Monitoring natural habitat/disturbance indicators (e.g., forest fires) is thus complementary to monitoring numbers and pattern of dispersion of land-use activities (exploration camps, etc.).

Fig. 5. Probable effects of an environmental change (hot, dry summer) and its direct effects on caribou behavior and on project-specific effects.

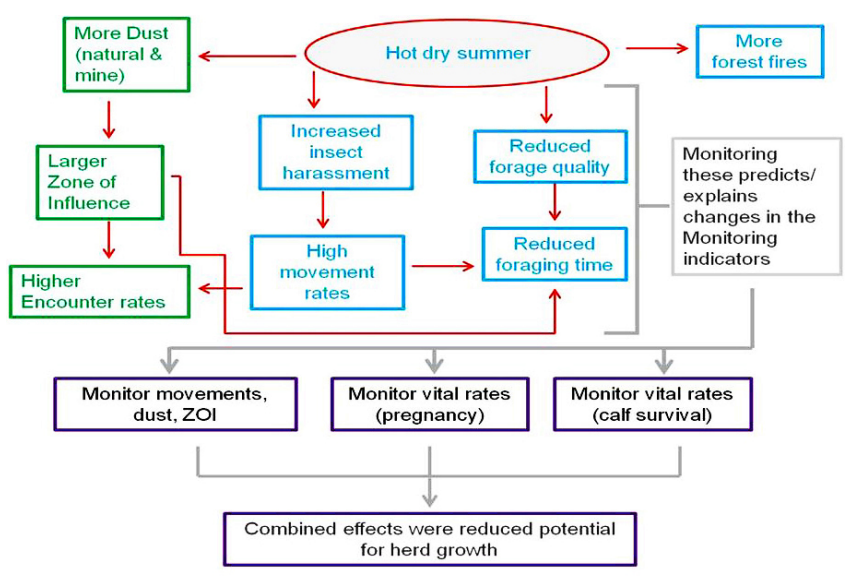

Some effects are based on measured relationships whereas others are hypothesized such as the relationship between dust and size of the zone of influence (Boulanger et al. 2012). Monitoring indices such as movement rates, weather indices for mosquito harassment, and time spent foraging can be used either to predict or explain changes in calf survival or pregnancy rates. Integrating natural environmental variability, anthropogenic change, and trends in climate change should involve integrative energetics modeling, as has been developed for the Porcupine caribou herd (Russell et al. 2005, White et al. 2014).

\section{DISCUSSION AND CONCLUSIONS}

Migratory tundra caribou experience wide fluctuations in numbers over the scale of decades. Consequently, management actions, monitoring, and the assessment of the role of industrial development projects need to account for these fluctuating numbers. The factors that limit annual productivity at population highs are not necessarily applicable when populations are in recovery. Further, the wide-ranging nature and sheer abundance of the species creates unique social, economic, political, and ecological challenges. It is with this backdrop that we need to assess and manage cumulative impacts of development. We maintain that the creation of an agreed upon collaborative framework that recognizes each partner's roles and responsibilities is an essential first step in this process. The proposed framework lays out the pathway to ensure that continuing development does not exceed thresholds and reduce the resilience of the human-caribou system.

We characterize our approach to monitoring and mitigating cumulative effects as a bottom-up approach because it applies specifics of monitoring and mitigation for a single valued ecological component: caribou in northern Canada. We have used flow diagrams to clarify how cumulative effects assessment, monitoring. and mitigation can be linked through adaptive management. Our response framework introduces three scales of mitigation (1) project-specific mitigation, (2) landscape-scale mitigation (i.e., dispersion and distribution of development projects across the landscape), and (3) population-level mitigation (i.e., modification of adult caribou survival over time as a tradeoff). These scales imply that adaptive management will have to be at the scale of the herd's annual range, which increases complexity from the number of interested parties, but strengthens planning and collaborative outcomes. A key to both the need for and the success of applying a cumulative effects framework will be to integrate across spatial scales. For example, there is more to be gained by integrating protection of calving grounds with maintaining pre-calving migration routes and ensuring winter ranges are intact.

Experience since the 1980s with managing caribou prompted our second objective to show how adaptive management of cumulative effects can be integrated into herd-level monitoring, assessment, and decision-making. The advantages are that it lays out a visible pathway for all the parties, including land and wildlife agencies and co-management boards that have regulatory responsibilities. Additionally, integrating cumulative effects and herd management focuses on sustainability and will clarify the possible limits and trade-offs in management actions between development and other actions such as harvest, predation control, and habitat management such as forest fires. While we 
acknowledge that adaptive management is neither simple nor easy (Walters 1997, Lee 1999), the difficulties and complexities are not insurmountable (Monroe et al. 2013).

Urgency for action is born of any accelerated rate and pace of development that, in the absence of a framework to mitigate and manage cumulative effects, may lead to local changes in caribou distribution and range fragmentation caused by roads as well as direct influences on caribou abundance. The cumulative effects of multiple concurrent or sequential development projects affect not only caribou behavior but also harvesting of caribou. Access for harvesting also includes the construction of all-season and winter roads, which can change harvesting levels. This tension between unmitigated cumulative effects from "unmanaged growth" of industrial development and harvesting rights is a key trade-off that is explicitly acknowledged in our proposed framework.

Assessing and managing cumulative effects relative to the condition of a caribou herd meets many of the steps outlined by Noble (2010) to put into place the institutional arrangements and capacity to implement effective cumulative effects management. Including cumulative effects in migratory tundra caribou management is not a novel idea (e.g., GNWT 2011). What is different about our proposed framework is that it shows how existing components can be linked through herd management, as people already have familiarity through working relationships and concepts.

Collectively, we already have the knowledge to make the proposed framework operational using a rules-based approach and narrative statements. The flexibility of the framework will allow it to accommodate biological, measurement, and model categories of uncertainty (Harwood and Stokes 2003). Making decisions while accommodating uncertainty and risk should include offsetting risks (e.g., conservative approaches that provide options for anticipating underestimated or unexpected effects), although adding details will be contingent on clearly defined terms such as trade-offs and offsets (e.g., ten Kate et al. 2004).

A limitation in applying cumulative effects approaches to managing caribou and development is that decision-makers rarely, if ever, know what industry and government are planning for the future, or at least very far into the future. A long-term planning process or, less formally, a dialog among industry, territorial, and provincial governments and aboriginal governments exchanging potential or real plans can contribute to a more focused approach to cumulative effects assessment.

A consistent theme in environmental assessments in the Northwest Territories is the need for greater involvement of aboriginal people in monitoring, mitigation, and management. It is these people who are most affected by even small incremental changes to caribou numbers and distribution. Integrating cumulative effects directly into herd management planning will strengthen aboriginal involvement, as herd management is moving toward shared responsibility (co-management) and accountability for the decisions about the sustainability of caribou herds.

Responses to this article can be read online at: http://www.ecologyandsociety.org/issues/responses. $\mathrm{php} / 6856$

\section{Acknowledgments:}

We thank the environmental assessment boards in northern Canada, as we have learned much while working with them. In particular, their on-line public registries give unprecedented access to the basis of assessments and amount of information. We also acknowledge those people who have shared their concerns and ideas during environmental assessments. Kathy Racher (Wek'èezhì Land and Water Board) helped us with adaptive management. We thank Gary Kofinas (University of Alaska), John Nishi, and three anonymous reviewers for their insightful comments.

\section{LITERATURE CITED}

Berger, J. 2004. The last mile: how to sustain long-distance migration in mammals. Conservation Biology 18(2):320-331. http://dx.doi.org/10.1111/j.1523-1739.2004.00548.x

Boulanger, J., B. Croft, and J. Adamczewski. 2014. An estimate of breeding females and analyses of demographics for the Bathurst herd of barren-ground caribou: 2012 calving ground photographic survey. File Report 142. Department of Environment and Natural Resources, Government of the Northwest Territories, Yellowknife, Canada.

Boulanger, J., A. Gunn, J. Adamczewski, and B. Croft. 2011. A data-driven demographic model to explore the decline of the Bathurst caribou herd. Journal of Wildlife Management 75 (4):883-896. http://dx.doi.org/10.1002/jwmg.108

Boulanger, J., K. G. Poole, A. Gunn, and J. Wierzchowski. 2012. Estimating the zone of influence of industrial developments on wildlife: a migratory caribou Rangifer tarandus groenlandicus and diamond mine case study. Wildlife Biology 18(2):164-179. http:// dx.doi.org/10.2981/11-045

Canter, L., and W. Ross. 2010. State of practice of cumulative effects assessment and management: the good, the bad and the ugly. Impact Assessment and Project Appraisal 28(4):261-268. http://dx.doi.org/10.3152/146155110X12838715793200

Copeland, H. E., K. E. Doherty, D. E. Naugle, A. Pocewicz, and J. M. Kiesecker. 2009. Mapping oil and gas development potential in the US Intermountain West and estimating impacts to species. Plos One 4(10): e7400. http://dx.doi.org/10.1371/journal. pone. 0007400

De Beers. 2012. Gahcho Kué Project, Environmental Impact Statement, Section 7. Key line of inquiry: caribou. Public Registry Document 80, 23 December 2010. MacKenzie Valley Review Board, Yellowknife, Canada. [online] URL: http://www. reviewboard.ca/upload/project document/EIR0607-001 EIS Section 7 Caribou_1294681839.PDF.

Duinker, P. N., and L. A. Greig. 2006. The impotence of cumulative effects assessment in Canada: ailments and ideas for redeployment. Environmental Management 37(2):153-161. http:// dx.doi.org/10.1007/s00267-004-0240-5

Government of the Northwest Territories (GNWT). 2011. Caribou forever - our heritage, our responsibility: a barren-ground caribou management strategy for the Northwest Territories 20112015. Department of Environment and Natural Resources, GNWT, Yellowknife, Canada. [online] URL: http://www.enr.gov. nt.ca/sites/default/files/strategies/2011-2015 barren-

ground caribou management_strategy.pdf. 
Greig, L. A., and P. N. Duinker. 2011. A proposal for further strengthening science in environmental impact assessment in Canada. Impact Assessment and Project Appraisal 29(2):159-165. http://dx.doi.org/10.3152/146155111X12913679730557

Gunn, A. 2003. Voles, lemmings and caribou - population cycles revisited. Rangifer 14(4):105-112. [online] URL: http://www. twodeadducks.net/rangifer/pdf/SI 14 105.pdf.

Gunn, A., K. G. Poole, and J. Wierzchowski. 2011. Migratory tundra caribou seasonal and annual distribution relative to Thaidene Nene, a national park reserve proposal in the East Arm of Great Slave Lake and Artillery Lake area, Northwest Territories. Unpublished report for Parks Canada, Fort Smith, Canada. [online] URL: http://landoftheancestors.ca/wp-content/uploads/2014/04/ Gunn-et-al-East-Arm-Park-caribou-final-report-Jan11.pdf.

Harwood, J., and K. Stokes. 2003. Coping with uncertainty in ecological advice: lessons from fisheries. Trends in Ecology and Evolution 18(12):617-622. http://dx.doi.org/10.1016/j.tree.2003.08.001

Jakle, A. 2012. Natural gas development and wildlife mitigation: a primer. William D. Ruckelshaus Institute of Environment and Natural Resources, Laramie, Wyoming, USA. [online] URL: http://www.uwyo.edu/haub/ruckelshaus-institute/ files/docs/ publications/2012-natural-gas-wildlife-mitigation.pdf.

Kennett, S., and D. Woynillowicz. 2007. A review of Alberta Environment's proposed regulatory framework for managing environmental cumulative effects. Unpublished report prepared for the Pembina Institute, Toronto, Canada. [online] URL: http:// www.pembina.org/reports/Pembina-review-AB-Env-ce.pdf.

Lee, K. N. 1999. Appraising adaptive management. Conservation Ecology 3(2): 3. [online] URL: http://www.consecol.org/vol3/iss2/ $\underline{\operatorname{art} 3 /}$.

Lutsel K'e Dene First Nation. 2012. Closing statement to the Gahcho Kue panel. Public Registry Document 410, 21 December 2012. Mackenzie Valley Review Board, Yellowknife, Canada. [online] URL: http://www.reviewboard.ca/registry/project_detail. php?project $\mathrm{id}=37 \&$ doc stage $=10$.

Lutz, D. W., J. R. Heffelfinger, S. A. Tessmann, R. S. Gamo, and S. Siegel. 2011. Energy development guidelines for mule deer. Mule Deer Working Group, Western Association of Fish and Wildlife Agencies, Tucson, Arizona, USA. [online] URL: http://www. muledeerworkinggroup.com/Docs/Energy_Development_Guidelines for Mule Deer 2013.pdf.

Monroe, M. C., R. Plate, and A. Oxarart. 2013. Intermediate collaborative adaptive management strategies build stakeholder capacity. Ecology and Society 18(2): 24. http://dx.doi.org/10.5751/ ES-05444-180224

Noble, B. 2010. Cumulative environmental effects and the tyranny of small decisions: towards meaningful cumulative effects assessment and management. Natural Resources and Environmental Studies Institute Occasional Paper 8. University of Northern British Columbia, Prince George, Canada. [online] URL: http:// www.unbc.ca/assets/nres/nresi_op_08_noble_2010.pdf.

Porcupine Caribou Management Board. 2010. Harvest management plan for the Porcupine caribou herd in Canada. Porcupine Caribou Management Board, Whitehorse, Canada. [online] URL: http://www.pcmb.ca/documents/Harvest $\% 20$ Management $\%$ 20Plan\%202010.pdf.

Racher, K. I., N. Hutchinson, D. Hart, B. Fraser, B. Clark, R. Fequet, P. Ewaschuk, and M. Cliffe-Phillips. 2011. Linking environmental assessment to environmental regulation through adaptive management. Integrated Environmental Assessment Management 7(2):301-302. http://dx.doi.org/10.1002/ieam.173

Russell, D. E., R. G. White, and C. J. Daniel. 2005. Energetics of the Porcupine caribou herd: a computer simulation model. Technical Report Series Number 431. Canadian Wildlife Service, Ottawa, Canada. [online] URL: http://publications.gc.ca/ collections/collection 2009/ec/CW69-5-431E.pdf.

Suter, G. W. II. 1990. Endpoints for regional ecological risk assessments. Environmental Management 14(1):9-23. http://dx. doi.org/10.1007/BF02394015

ten Kate, K., J. Bishop, and R. Bayon. 2004. Biodiversity offsets: views, experience, and the business case. IUCN, Gland, Switzerland, and Insight Investment, London, UK. [online] URL: http://cmsdata.iucn.org/downloads/bdoffsets.pdf.

Tlicho Government. 2012. Closing statement to the Gahcho Kue panel. Public Registry Document 416, 21 December 2012. Mackenzie Valley Review Board, Yellowknife, Canada. [online] URL: http://www.reviewboard.ca/upload/project document/ EIR0607-001 Tlicho Government Presentation.PDF.

Walters, C. 1997. Challenges in adaptive management of riparian and coastal ecosystems. Conservation Ecology 1(2): 1. [online] URL: http://www.consecol.org/vol1/iss2/art1/.

Walters, C. J., and C. S. Holling. 1990. Large-scale management experiments and learning by doing. Ecology 71(6):2060-2068. http://dx.doi.org/10.2307/1938620

White, R. G., D. E. Russell, and C. J. Daniel. 2014. Simulation of maintenance, growth and reproduction of caribou and reindeer as influenced by ecological aspects of nutrition, climate change and industrial development using an energy-protein model. Rangifer, in press. 